\title{
Rádio Online como ferramenta corporativa de comunicação: proposta para a empresa brasileira de correios e telégrafos
}

\author{
Online Radio as a tool for corporate communication: proposal for \\ a Brazilian company post and telegraph
}

\author{
Silvio Junior Triquês
}

\begin{abstract}
Pós-Graduando em Marketing pela Universidade do Contestado (UNC); Bacharel em Comunicação Social - Habilitação em Rádio e Televisão pela Universidade do Oeste de Santa Catarina (UNOESC), Joaçaba, SC - Brasil, e-mails: silviotriques@bol.com.br; triques1@hotmail.com
\end{abstract}

\section{Resumo}

Este artigo parte da premissa de que os profissionais da comunicação devem buscar novas possibilidades de utilização dos meios disponíveis; afinal, vive-se a era da tecnologia aliada à informação, e o rádio, em razão do seu poder de abrangência e de suas características, como a atualidade e o imediatismo da informação, deve acompanhar esses avanços e adaptar-se a novas formas de transmissão. Assim, este trabalho apresenta o rádio online como ferramenta corporativa de comunicação. A comunicação empresarial e seus processos comunicacionais constituem o objeto de estudo desta pesquisa, já que, como ramificação das ciências comunicacionais, tratam do conjunto de instrumentos que as empresas utilizam para falar e se fazer ouvir, seja com seu público interno, seja com o externo. Com o objetivo de desenvolver estudo sobre o campo da comunicação empresarial, este trabalho apresenta conceitos de comunicação empresarial e rádio online e a análise dos dados obtidos mediante pesquisa quantitativa realizada com colaboradores da Empresa Brasileira de Correios e Telégrafos, cujo resultado é utilizado como subsídio para o estudo da implantação e programação da rádio. O conteúdo programático proposto neste trabalho visa a complementar e unificar os processos comunicacionais já existentes na empresa.

Palavras-chave: Rádio online. Comunicação empresarial. Endomarketing.

\section{Abstract}

The premise of this article takes the analysis that communication professionals must seek new possibilities to use the resources available, ultimately lives up to the age of technology coupled with the information, and radio, 
hustle exercise of its comprehensiveness and characteristics, such as currency and immediacy of information, must accompany these developments and adapt to new forms of transmission. Thus, this paper presents the online radio as a tool of corporate communication. The business communication and their communication processes are the subject of this research, since, as branch of science comunicacionais, deal with the set of tools that companies use to speak and be heard, either with its internal, or external. Aiming to develop a study on the field of corporate communication, this article introduces the concepts of business communication and internal marketing and analysis of the obtained quantitative research conducted with colleagues from the Brazilian Post and Telegraph, whose result is used as input for study the implantation and programming of the radio. The curriculum proposed in this paper aims to complement and unify the existing communication processes in the company.

Keywords: Online radio. Corporate communications. Endomarketing.

\section{Introdução}

Ao analisarmos as transformações do mundo moderno, precisamos ter em mente a importância da comunicação nos processos que permeiam as relações humanas e sociais, pois vivemos em uma era de informação e avanços tecnológicos. A comunicação corporativa é hoje a área responsável por transformar informação em conhecimento produtivo; por isso é importante a disseminação e o desenvolvimento da informação dentro das empresas. Cada vez mais, elas estão se mostrando dispostas a ouvir seus colaboradores, sugestões e críticas sobre seus produtos e a prestação de seus serviços.

Uma empresa como os Correios pode apresentar falhas no processo comunicacional no que tange o acesso à informação, pois empresas de grande porte possuem a tendência de comunicação vertical, ou seja, feita de cima para baixo a partir de um sistema em que a informação é gerada ou processada pelos dirigentes e destina-se aos funcionários.

O presente trabalho justifica-se sob o propósito de horizontalizar tal processo por meio da implantação de uma rádio corporativa online, com capacidade de unificar os meios comunicacionais existentes na empresa; por isso se faz necessário pensar em um sistema que contemple efetivamente a participação dos funcionários em todos os processos. Outro fator relevante nessa proposta é o conteúdo programático da rádio, de acordo com dados obtidos em pesquisa realizada. É de interesse dos funcionários que a rádio disponibilize campanhas, notícias sobre a estrutura da empresa e as principais matérias dos jornais que circulam dentro e fora da organização.

O principal objetivo ao desenvolver este trabalho consistiu em analisar a viabilidade de implantação de uma rádio corporativa online para a Empresa Brasileira de Correios e Telégrafos. Com a finalidade de aprimorar o debate acerca do estudo dos processos comunicacionais, o projeto será desenvolvido sob dois aspectos que se complementam: primeiro, a fundamentação teórica, baseada em pesquisas sobre a literatura da área e sites relacionados ao tema do projeto; segundo, a experiência do acadêmico decorrente da vivência profissional, observando-se a necessidade do estudo e possível implantação de rádio corporativa online, junto à Empresa Brasileira de Correios e Telégrafos.

O levantamento de dados será quantitativo e baseado em amostra regional por meio de questionários aos funcionários de 20 agências pertencentes à Região de Vendas 04 (ou Reven 04) com sede em Joaçaba. A Região de Vendas 04 envolve 74 agências próprias, 11 franquias e 54 AGCs; trata-se da maior regional em extensão territorial da diretoria de Santa Catarina.

\section{Comunicação empresarial}

As transformações na sociedade moderna impuseram à comunicação papel fundamental no plano estratégico de valorização das empresas, partindo do pressuposto de que os funcionários constituem a base para o alcance dos objetivos do negócio. $\mathrm{Na}$ condição de ferramenta funcional qualitativa, cabe à comunicação interna o desafio de impulsionar o desempenho e o sucesso financeiro de uma empresa, deixando de ser mera divulgadora de informações e passando a compartilhar tal processo, possibilitando o comprometimento de todos com a missão, a visão, a estratégia e os valores organizacionais. 
De acordo com Bahia (1995, p. 9), os sistemas de informação pouco evoluíram até a década de 1990, mas, com o avanço da informática, passaram a conjugar recursos capazes para integrar empresas e modernizá-las, em busca da qualidade total. A comunicação empresarial tornou-se uma função complexa e passou a ser objeto de estudo, pois se insere num conceito de permanência e deriva da cultura empresarial.

Podemos compreender comunicação comoum processo social básico, e informação como um processo básico da comunicação. Em ambos os casos, a comunicação empresarial implica uma estratégia a ser praticada de modo competente [...] a rede de informações de uma empresa não se limita a praticar técnicas de comunicação. Mais que isso, faculta à organização o contato direto com seus públicos, de forma, a saber, o que os empregados e os consumidores pensam ou querem (BAHIA 1995, p. 15).

Tão importante quanto os produtos e serviços prestados, a comunicação empresarial deve coexistir como uma das mais relevantes ações estratégicas da empresa, tendo por objetivo a melhoria de produtos e serviços, a valorização dos recursos humanos ou a própria construção de imagem junto aos consumidores, fornecedores e colaboradores.

A comunicação empresarial cresceu ultrapassando as fronteiras da informação de distribuição interna. Para Bahia (1995, p. 40), a televisão e o rádio, sobretudo, constituem os intermediários mais adequados para a transmissão e o conhecimento das ideias, das ações, do pensamento e das opiniões do empresariado, pois estes têm um alcance imediato e sua audiência é heterogênea, tendo em vista que a comunicação empresarial se processa na perspectiva do mercado, seja local, regional ou internacional.

\section{Internet como veículo de comunicação}

A internet é imensa e é usada das mais diferentes formas. Monteiro (2001) destaca que a internet foi criada como um veículo de comunicação alternativo e que atualmente ainda é utilizada com esse propósito. Delarbre (2005) ressalta que apenas uma pequena parte dos internautas aproveita a rede em suas proporções e a abundante informação que nela está. Menos invasivo que o telefone e menos formal que uma carta, a internet é um meio de comunicação interpessoal.

A internet atinge proporções mundiais no sistema de redes de computadores interligados, alcança mais de 150 países e reúne aproximadamente 300 milhões de computadores com mais de 400 milhões de usuários (DIZARD, 2000).

Segundo Barbosa e Rabaça (2001), os meios de comunicação de massa possuem algumas características:

a) são operados por complexas organizações, envolvendo diversos profissionais, com diferentes habilidades;

b) são capazes de difundir suas mensagens para milhares ou até milhões de pessoas, utilizando grandes recursos tecnológicos sustentados em sua maioria pela publicidade;

c) falam para uma audiência numerosa, heterogênea e geograficamente diferente;

d) exercem um tipo de comunicação unilateral, mesmo que haja feedback.

Por um lado, a internet possui, de certa forma, ao menos as três primeiras características citadas. Por outro lado, diferentemente do que ocorre na comunicação de massa, a comunicação na internet pode ser feita apenas por uma pessoa com um simples computador e uma linha telefônica, disponibilizando conteúdos para o grande público. Necessariamente, não precisa acontecer no mesmo sentido porque, em razão das suas características de hipertexto, a internet permite que a pessoa faça seu próprio caminho para o acesso aos conteúdos, determinando quando e qual informação quer receber; "sua postura deixa de ser a do receptor para ser o espectador e entra em cena o usuário" (MONTEIRO, 2001, p. 4).

Cabe dizer que a internet é um veículo de comunicação revolucionário, que apresenta aspectos nunca previstos no cenário da comunicação. A internet veio para revolucionar os meios de comunicação, pois até o final do século XX a divulgação pública de informações não estava ao alcance de pessoas comuns; como sabemos, era restrita a uma elite que detinha o 
controle dos veículos responsáveis pela informação, até porque o acesso a esses meios estava limitado aos recursos financeiros dos cidadãos

Com o advento da internet, isso mudou significativamente. Não são mais necessários grandes investimentos para se ter um meio de produção e distribuição de informações. A internet cede lugar para "muitas pessoas se comunicarem com muitos receptores, que respondem de volta, e assim criam o efeito clássico da comunicação" (DIZARD, 2000, p. 23).

Com a possibilidade de assumir o controle da tecnologia, "usuários e criadores podem tornar-se a mesma coisa" (CASTELLS, 1999, p. 5). Para Castells, o que ocorre nessa sociedade, estruturada na informação, é a "capacidade de gerar, processar e aplicar de forma eficiente a informação baseada em conhecimentos" é comparável à posse dos meios de produção de bens na época da sociedade industrial (CASTELLS, 1999, p. 5).

A era da internet tem várias implicações no mundo empresarial e se transformou numa valiosa ferramenta que permite às empresas enviar informações de maneira rápida e ampla. Entretanto, e infelizmente, não há diferenciação entre notícias verdadeiras e falsas, e ambas são transmitidas com a mesma velocidade. No entanto, o uso positivo da internet permite às empresas conhecimento sobre necessidades e queixas dos consumidores, bem como monitorar e planejar ações que atendam ao público e fortaleçam a reputação da empresa.

\section{Rádio online}

O advento do rádio na internet teve início em setembro de 1995 no Texas, com a KLIF de Dallas, que se tornou a primeira emissora comercial a transmitir de forma contínua e ao vivo um programa de rádio por meio da rede.

No Brasil, de acordo com Barbosa Filho (1996), a rádio Itatiaia foi a pioneira. Desde a primeira transmissão em 1997 até o ano 2000, 191 emissoras já haviam adotado o sistema de transmissão online.

De acordo com Kuhn (2001), o crescimento acelerado de rádios que adotam a transmissão via internet deve ser atribuído à facilidade do sistema RealAudio Player, lançado em 1995 e difundindo plenamente em 1997, que possibilita sintonizar sinais sonoros em tempo real pela rede, sendo necessário apenas baixar o arquivo, instalá-lo, entrar no site da emissora e clicar no local indicado.

Apesar do número de rádios na internet, a recepção de áudio por meio deste sistema possui limitações. Abrir mais páginas, além da rádio que se está ouvindo, não é recomendável, pois isso pode interferir na recepção dos dados pelo computador do usuário. A qualidade da placa de som instalada no computador também constitui fator determinante na qualidade do áudio, pois as rádios funcionam no sistema de bufferização, ou seja, armazenam dados capazes de sustentar a apresentação por determinado tempo.

Com a migração do rádio para a internet, cessam as disputas por concessões, frequências e investimentos em equipamentos, afinal qualquer usuário pode criar sua rádio virtual.

Deacordo com Kuhn(2001,p. 43), nas rádios convencionais, o contato com os ouvintes somente tem o imediatismo quando é feito por telefone, enquanto que, em uma rádio online, esse contato pode acontecer pore-mailou chatem temporeal, uma vezqueointernauta está naquele momento, navegando no site. A tendência do rádio na internet é seguir para a quarta mídia, e isso se dá pela observação de dois mil sites de emissoras de rádio que são modelos na rede. Como destaca Kuhn (2001), o rádio online pode dispor aos leitores/ ouvintes informações institucionais, áudio contínuo ou não, vídeo e animação, guias específicos de utilidade pública, fotos, textos informativos e a participação do público por meio de mural de recados. A tendência segue na utilização de câmeras nos sites de rádio para que o leitor/ouvinte possa agregar imagem e, assim, estreitar a relação de proximidade com a informação.

\section{Pesquisa}

A comunicação empresarial assume, cada vez mais, dimensões globais e nos impulsiona a gerar e repassar informações de nível organizacional para os diversos públicos com que a empresa se relacionaimprensa, comunidade, clientes, parceiros, acionistas e, principalmente, funcionários.

Partindo da análise conceitual descrita, e com o objetivo de aprimorar o projeto, segue pesquisa quantitativa realizada com questionários de autopreenchimento.

A pesquisa foi realizada com o intuito de detectar o grau de aceitação dos funcionários em ouvir 
uma rádio online, identificar o tipo de informação que ele gostaria de receber por esse veículo de comunicação e conhecer a realidade na qual se aplica o objeto de pesquisa. Outros objetivos, implícitos na pesquisa, também foram atingidos, entre eles: identificar as percepções dos colaboradores em relação à forma de comunicação da empresa, detectar aceitação ou reprovação com relação à mudanças na organização, propor novas formas para uma comunicação mais efetiva e eficaz no ambiente interno.

O universo pesquisado é composto de 20 agências, escolhidas aleatoriamente na lista de unidades pertencentes à Reven 04 com sede em Joaçaba. A Reven 04 envolve 74 agências próprias, 11 franquias e 54 AGCs; trata-se da maior regional em extensão territorial da diretoria de Santa Catarina. Nessa amostragem, levando em consideração o número de funcionários das agências escolhidas para a realização da pesquisa, cerca de 70 questionários deveriam ser distribuídos, ao que retornaram 66 deles, garantindo, assim, a utilização de uma amostra representativa do universo, com nível de confiança de aproximadamente 95\%.

Segue análise dos dados obtidos na pesquisa. O Gráfico 1 apresenta a faixa etária dos colaboradores pesquisados. Para fins de pesquisa, os colaboradores foram divididos em três grandes grupos, com faixa etária entre 18 a 25 anos, 25 a 40 anos e acima de 40; não coube pesquisar se havia alguém abaixo dos 18 , pois é exigência mínima quando da investidura do cargo por meio de concurso público a idade mínima de 18 anos.

Percebemos por meio dos dados que $59 \%$ dos entrevistados possuem entre 25 e 40 anos, o que indica um público ainda jovem cuja faixa etária servirá como base para a elaboração da programação da rádio.

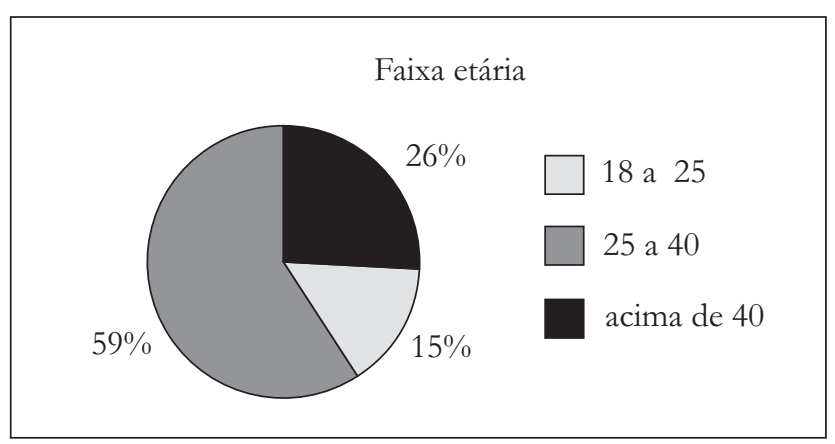

Gráfico 1 - Faixa etária

Fonte: Dados da pesquisa.
No Gráfico 2, a pergunta foi se os entrevistados ouviam rádio: $86 \%$ responderam que sim, o que comprova o rádio como veículo de grande poder de alcance e de conteúdo de fácil assimilação. Podemos perceber pela quantidade de pessoas na sociedade atual que ainda ouvem rádio de forma portátil, embora esse meio tenha sofrido grandes mudanças tecnológicas; prova disso é este projeto, que trata de rádio online - esse meio jamais perdeu sua credibilidade.

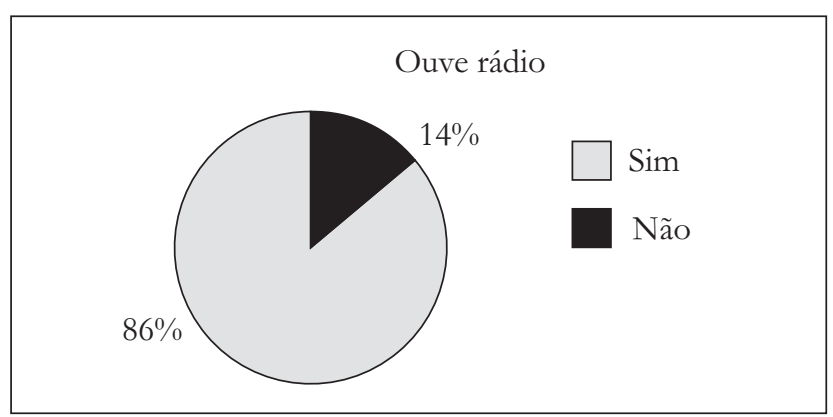

Gráfico 2 - Ouve rádio

Fonte: Dados da pesquisa.

O Gráfico 3 apresenta os dados sobre a frequência com que os entrevistados ouvem rádio: 53 $\%$ ouvem rádio todos os dias, quer seja no ambiente de trabalho, ou no caminho entre a casa e o trabalho; apenas $12 \%$ não ouvem rádio, o que evidencia o rádio como companheiro de todas as horas, sem a obrigatoriedade de interromper as atividades que se está realizando.

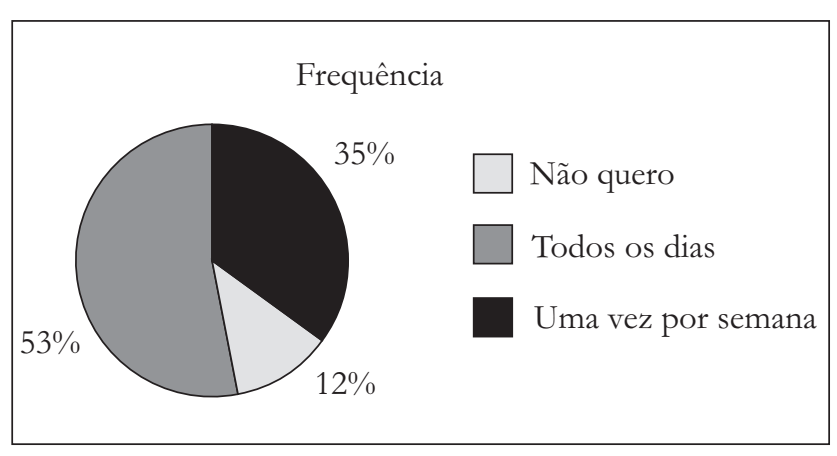

Gráfico 3 - Frequência

Fonte: Dados da pesquisa.

No Gráfico 4 constam os dados a respeito do conhecimento e do grau de importância dos entrevistados sobre o que é uma rádio corporativa. 
Houve um certo equilíbrio nos dados, mas a maioria, 38\%, nunca ouviu falar em rádio corporativa, o que justifica ainda mais a implantação dentro da empresa e o envolvimento dos colaboradores nessa ferramenta de gestão e comunicação; é preciso que os colaboradores saibam que existem outras formas de se ter acesso às informações da empresa.

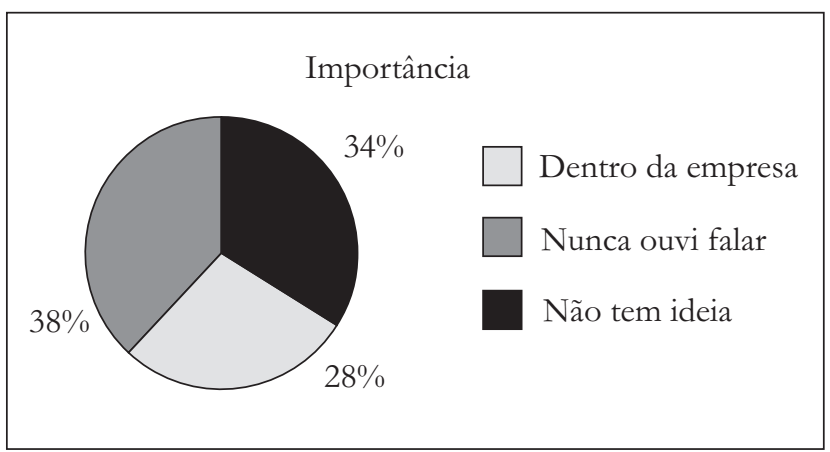

Gráfico 4 - Importância

Fonte: Dados da pesquisa.

Por seu caráter de entretenimento, percebemos, por meio do Gráfico 5, que, com a implantação de uma rádio corporativa online, $33 \%$ dos entrevistados gostariam que fosse disponibilizada música, seguido de notícias da empresa (24\%) e notícias dos principais jornais em circulação do estado. Percebemos aqui que, embora a maioria desconheça o que é uma rádio corporativa, seu modelo está atrelado ao conteúdo e programação das rádios que costumamos ouvir.

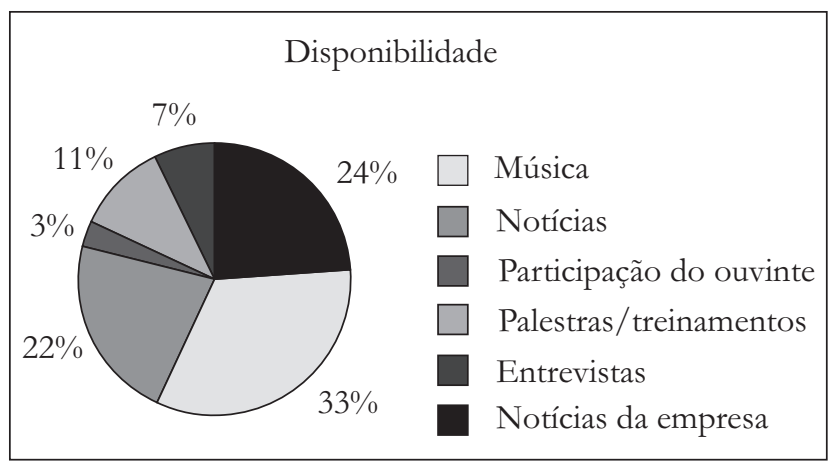

Gráfico 5 - Disponibilidade

Fonte: Dados da pesquisa.

O Gráfico 6 contém os dados da pesquisa sobre estilos musicais, tendo em vista que a música, como descrito no gráfico anterior, tem $33 \%$ da preferência. A seguir há uma amostragem sobre a preferência musical dos entrevistados.

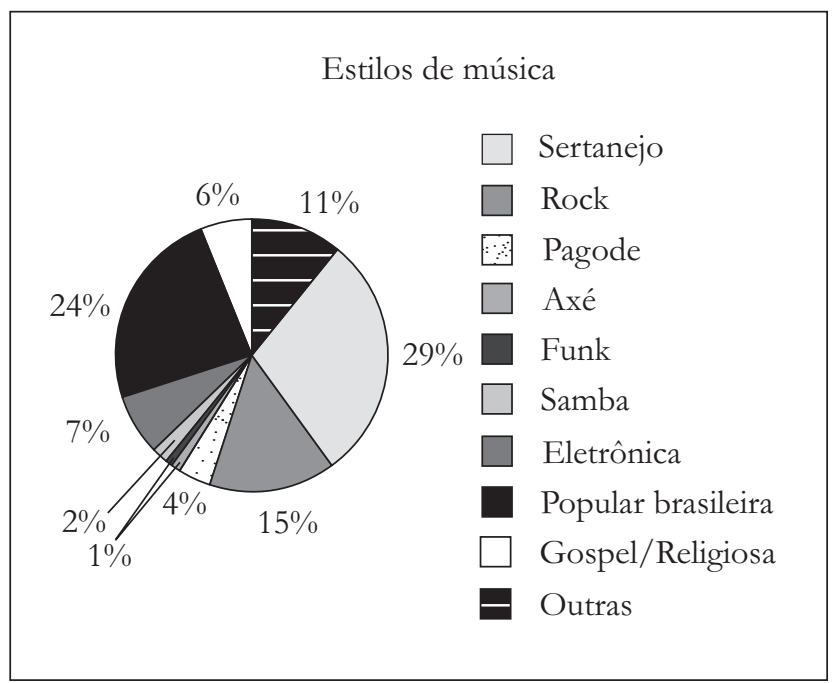

Gráfico 6 - Estilos de música

Fonte: Dados da pesquisa.

Podemos perceber que, de maneira geral, os ouvintes são ecléticos, gostam um pouco de cada estilo, o que possibilita trabalhar com uma programação diversificada.

No Gráfico 7 temos a informação de que $86 \%$ dos entrevistados consideram que a implantação de uma rádio corporativa online poderia trazer benefícios aos funcionários e à empresa. Relaciono esse dado com o Gráfico 2, que apresenta o mesmo resultado; essa relação indica que os 14\% dos entrevistados que não ouvem rádio são os mesmos $14 \%$ que responderam que a implantação de uma rádio corporativa não poderia trazer melhorias.

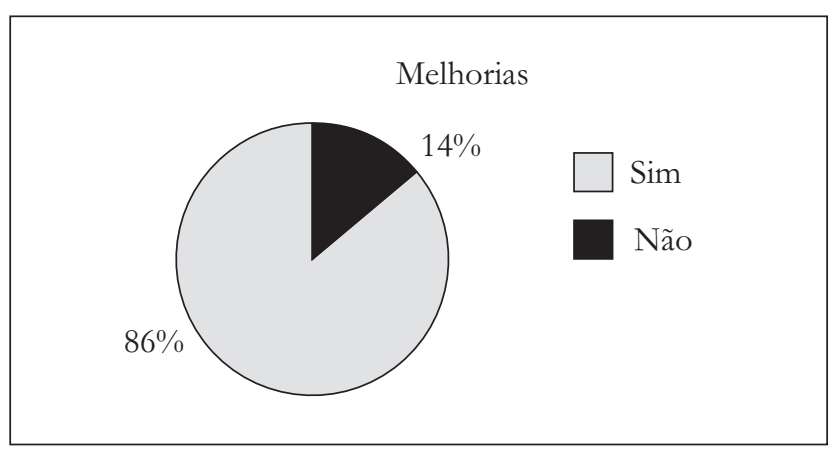

Gráfico 7 - Melhorias

Fonte: Dados da pesquisa. 
No Gráfico 8 temos os dados sobre a expectativa da implantação de uma rádio corporativa online nos Correios. $88 \%$ dos entrevistados são favoráveis à implantação, pois acreditam que ela pode trazer melhorias; entre eles $17 \%$ acham que teriam sua produtividade rendimento no trabalho aumentados e $71 \%$ acreditam que a facilidade de acesso às informações seria o principal benefício.

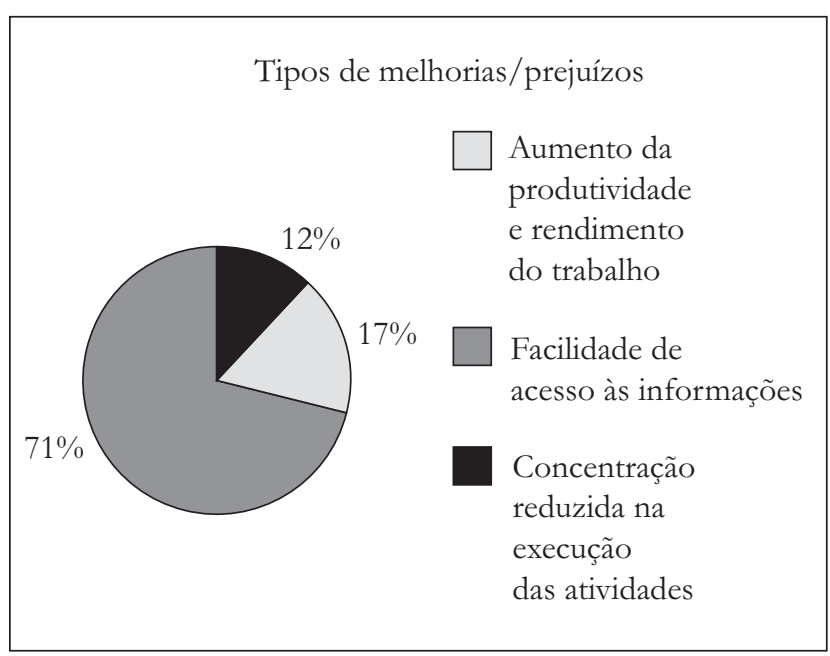

Gráfico 8 - Melhorias e prejuízos

Fonte: Dados da pesquisa.

Aqui há um dado bastante interessante quando relacionado aos dados obtidos no Gráfico 5. Em análise dos questionários, percebi que as pessoas que responderam que seria desnecessária a implantação de uma rádio corporativa também responderam que esse meio de comunicação poderia reduzir a concentração nas atividades realizadas. Além disso, há relação direta com os dados do Gráfico 3, em que $12 \%$ dos entrevistados não ouvem rádio.

Para concluir a análise dos dados obtidos na pesquisa, é pertinente, sobre a viabilidade de implantação ou não de uma rádio online, conhecer as reais vantagens desse tipo de projeto para a empresa.

A rádio online representa uma economia com custos de telefone, fax e papel para a distribuição de informações; economia no desenvolvimento de aplicações em rede; facilidade de acesso a informações corporativas; comunicação mais rápida, eficiente e de fácil compreensão; além das vantagens intangíveis, como a integração das diversas áreas da empresa e a mudança cultural da própria organização.
Partindo da análise de custos e benefícios, que geralmente se mostra favorável à decisão de implantação de uma rádio online, existe outro fator fundamental que se torna estratégia: hoje em dia são poucas as empresas que dispõem de uma rádio online corporativa, o que se torna um diferencial e fator primordial no que tange uma comunicação integrada e de fácil acesso, afim de que sejam alcançados os objetivos estabelecidos pela empresa.

A implantação de uma rádio online envolve uma série de investimentos com hardware e software, pessoal e treinamento operacional. No entanto, a implantação de uma rádio online para os Correios é facilitada porque a empresa já possui um ambiente tecnológico: computadores interligados em uma rede e uma plataforma de intranet. Como a rádio online se baseia em uma tecnologia padrão, o conjunto tecnológico existente na empresa pode ser adaptado, reduzindo os gastos. Há, porém, a necessidade de melhoria de hardware e de software para os servidores (hojejá é possível encontrar servidores de programas completamente gratuitos).

Com base em estudos na área, não há como estabelecer ou determinar valores reais para os custos da implantação. O que se sabe é que, na relação custo/benefício, ela é extremamente vantajosa.

A implantação de uma rádio online em uma empresa, seja de pequeno, médio ou grande porte, deve ocorrer de forma cautelosa e progressiva, iniciando com a veiculação de um protótipo e alguns poucos serviços personalizados até que se consiga o envolvimento de todos os funcionários, pois a tendência é que uma rádio online revolucione a comunicação corporativa, alterando a maneira de disseminar as notícias dentro da própria empresa, estabelecendo base para o relacionamento interpessoal e facilitando a prática da empatia e afetividade entre os funcionários.

Finalizando a análise da pesquisa realizada, o fato é que, no Brasil, não existe veículo de comunicação tão popular quanto o rádio; esse meio carrega uma enorme vantagem ao permitir o acesso a informações em situações reais. Com a rádio online, os funcionários dos Correios vão poder participar diretamente, criando, quem sabe, um programa que divulgue seus talentos, com poesias, músicas, entrevistas e leituras, pois o rádio como veículo de comunicação amplia o alcance de cidadania por meio da vOz e ainda desenvolve a expressão, exercita o 
raciocínio lógico e permite conhecer e utilizar novas tecnologias, estimulando a imaginação e a criatividade, e concretizando o conhecimento profissional.

\section{Conclusão}

Após o término deste trabalho, entendemos a comunicação interna como fundamental no sucesso de uma empresa ou organização, e a maneira como o empresário lida com as informações constitui fator determinante para a imagem da empresa ou organização junto ao público interno ou externo, e isso perpassa os lucros e as metas.

São inúmeras as possibilidades de uso dos meios de comunicação dentro de uma empresa, mas se no âmbito empresarial comunicamos aos funcionários como fazíamos há cinco anos, estamos fugindo dos avanços tecnológicos que nos circundam; essa foi a base da pesquisa, propor a implantação de uma rádio online corporativa como alternativa cabível que unificasse os processos comunicacionais existentes na Empresa Brasileira de Correios e Telégrafos afim de aprimorar o acesso às informações, interligando os diversos níveis e promovendo uma comunicação mais próxima de todos os colaboradores.

Hoje percebemos que o campo da pesquisa científica na área da comunicação é muito vasto, e a universidade desempenha papel fundamental no que tange o incentivo a essa prática por meio de ações educacionais que permeiam a construção do perfil profissional a universidade viabiliza a evolução dos processos comunicacionais. Esperamos que esta pesquisa contribua de maneira significativa para o estudo da comunicação e sua relação com o mundo em que vivemos, pois ela entrelaça a vivência profissional com o conhecimento empírico.

\section{Referências}

BAHIA, J. Introdução à comunicação empresarial. Rio de Janeiro: Mauad, 1995.

BARBOSA, G. G.; RABAÇA, C. A. Dicionário de comunicação. 2. ed. Rio de Janeiro: Campus, 2001.

BARBOSA FILHO, A. Rádionainternet: concessão para quê? São Paulo: RTV - Universidade de São Paulo, 1996.
CASTELLS, M. A era da informação: economia, sociedade e cultura. 2. ed. São Paulo: Paz e Terra, 1999. v. 1.

DELARBRE, R. T. Internet es el futuro. In: MELO, J. M. de; SATHLER, L. Direitos à comunicação na sociedade da informação. São Bernardo do Campo: UMESP, 2005. p. 203-211.

DIZARD Jr., W. A nova mídia: a comunicação de massa na era da informação. Rio de Janeiro: Jorge Zahar, 2000.

KUHN, F. O rádio na internet: rumo à quarta mídia. In: INTERCOM - Sociedade Brasileira de Estudos Interdisciplinares da Comunicação, Simpósio da Pesquisa em Comunicação da Região Sudeste, Vitória-ES, 8., 2001, Vitória. Anais... Vitória: Intercom, 2007. Disponível em: <http://www.intercom.org.br/papers/viii-sipec/ gt01/31\%20-\%20Fernando $\% 20$ Kuhn $\% 20-\% 20$ trabalho\%20final.htm>. Acesso em: 20 nov. 2010.

MONTEIRO, L. A internet como meio de comunicação: possibilidades e limitações. In: CONGRESSO BRASILEIRO DA COMUNICAÇÃO, 24., 2001, Campo Grande. Anais... Campo Grande: INTERCOM, 2001. Disponível em: <http:// http://galaxy.intercom.org.br:8180/dspace/bitstream/1904/4714/1/ NP8MONTEIRO.pdf $>$. Acesso em: 20 nov. 2010.

Recebido: 21/04/2011 Received: 04/21/2011

Aprovado: 24/05/2011

Approved: 05/24/2011 